\title{
A utilização dos meios de comunicação como fator de inclusão social
}

\author{
The use of the media as a factor of social inclusion
}

\section{El uso de los medios de comunicación como factor de inclusión social}

\author{
Cláudia Ruas ${ }^{1}$ \\ Inara Souza Silva ${ }^{1}$ \\ Lorena Arantes do Socorro ${ }^{1}$
}

Recebido em: 04/09/2020; revisado e aprovado em: 04/10/2020; aceito em: 04/10/2020 DOI: http://dx.doi.org/10.20435/inter.v22i3.3148

\begin{abstract}
Resumo: : O Rádio Z é um projeto de extensão do curso de Publicidade e Propaganda (PP) em parceria com o curso de Jornalismo da Universidade Católica Dom Bosco e a Associação Pestalozzi de Campo Grande (APCG). A metodologia consiste na edição de um programa de um minuto a ser veiculado em emissoras locais. Constata-se que os alunos colocam em prática a teoria recebida em sala de aula e conhecem outra realidade. Para os alunos da Pestalozzi, observa-se uma melhora da autoestima e o aprimoramento das técnicas vocais. Palavras-chave: rádio; Publicidade e Propaganda; Jornalismo; inclusão social.

Abstract: The Rádio $Z$ is an extension project of the Publicity and Propaganda (PP) course in partnership with the Journalism course at the Catholic University Dom Bosco and the Pestalozzi Association of Campo Grande (APCG). The methodology consists of editing a one-minute program to be broadcast on local stations. It appears that students put into practice the theory received in the classroom and know another reality. For Pestalozzi students, there is an improvement in self-esteem and improvement of vocal techniques.
\end{abstract}

Keywords: radio; Advertising and Marketing; Journalism; social inclusion.

Resumen: El Rádio Z es un proyecto de extensión del curso de Publicidad y Propaganda (PP) en alianza con el curso de Periodismo de la Universidad Católica Dom Bosco y la Asociación Pestalozzi de Campo Grande (APCG). La metodología consiste en editar un programa de un minuto para ser transmitido en las estaciones locales. Se percibe que los alumnos ponen en práctica la teoría recibida en el aula y conocen otra realidad. Para los estudiantes de Pestalozzi, hay una mejora en la autoestima y mejora en las técnicas vocales.

Palabras clave: radio; Publicidad y Propaganda; Periodismo; inclusión social.

\section{INTRODUÇÃO}

O projeto intitulado Rádio Z: Informação especial para você, do curso de Publicidade e Propaganda em parceria com o curso de Jornalismo da Universidade Católica Dom Bosco (UCDB), concretiza-se com a participação dos alunos da Associação Pestalozzi de Campo Grande (APCG). A metodologia é aplicada da seguinte forma: os alunos do curso de Jornalismo fazem a pesquisa e produzem a pauta após a discussão com a equipe, e os extensionistas do curso de Publicidade criam jingle/spot e a trilha sonora para cada programa gravado, com temas de utilidade pública, reforçando que a cidadania é uma questão de informação e de atitude.

Este artigo retrata a importância do meio de comunicação radiofônico e como seu valor pode ir além da informação e do entretenimento. De forma criativa, o rádio pode se transformar na concretização da cidadania e da inclusão social.

Como consideração final, pode-se afirmar que, para a instituição, esse projeto inédito agrega valor à sua marca. Para os acadêmicos, é possível visualizar como a teoria recebida em sala de aula pode ser aplicada na prática e, mais ainda, como sua profissão pode ter um componente social. Por fim, para os alunos da APCG, há uma proximidade e convívio com outras realidades e pessoas, melhorando a autoestima, aprimorando técnicas vocais, perdendo a timidez, além do

\footnotetext{
${ }^{1}$ Universidade Católica Dom Bosco (UCDB), Campo Grande, Mato Grosso do Sul, Brasil.
} 
reconhecimento de talentos individuas, provando que, mesmo dentro de seus limites, não há limites para informar, entreter e educar por meio do meio radiofônico.

\section{A INDISSOCIABILIDADE E A EXTENSÃO UNIVERSITÁRIA}

Para que as instituições se intitulem de Universidade, seja ela pública, seja ela privada, é preciso a indissociabilidade entre ensino, pesquisa e extensão. De acordo com Durhan e Sampaio (1995), até 1985 as universidades se concentravam, prioritariamente, no setor público, e somente no período de 1985 a 1996 é que as universidades privadas começaram a se expandir em função da Constituição Federal Brasileira de 1988. No que se refere ao setor privado, este pode ser separado em duas categorias: as IES sem fins lucrativos, as comunitárias, como é o caso da UCDB; e as IES com fins lucrativos particulares (BITTAR, 2000).

De acordo com Ruas (2015), para ser classificada como universidade, obrigatoriamente, a IES deve oferecer atividades de ensino, pesquisa e extensão, bem como pode criar seus próprios cursos sem a necessidade de solicitar autorização ao Ministério da Educação (MEC). Sua extensão deve ser constituída de serviços ou atendimentos para a sociedade em várias áreas do conhecimento.

A extensão, como parte da dissociabilidade, consta da Lei 5.540/68, da Reforma Universitária evidenciada no artigo 17 (BRASIL, 1968). Nesta mesma lei, em seu artigo 20, a extensão é considerada como a forma por meio da qual as instituições de ensino superior estenderão à comunidade as atividades de ensino e os resultados da pesquisa (BITTAR, 1999).

Extensão deve ser entendida como projetos que objetivam contribuir para o desenvolvimento socioeconômico de comunidades brasileiras, principalmente aquelas marcadas pela pobreza, vítima de extrema desigualdade regional existente no país.

Ainda sobre a extensão, o autor Síveres (2005) afirma que extensão deve ser vista como fator determinante de integração entre o ato educativo e a práxis social, a articulação entre compreender a realidade e responder aos seus desafios. Outro fator importante que cita o autor é que a extensão também é a interação entre o questionamento ético e o engajamento político em que os acadêmicos, professores e a comunidade passam a ser sujeitos do ato de aprender, de produzir conhecimentos e tecnologias, além de formar pessoas comprometidas com a realidade social.

Bittar (1999, p. 215) expõe o pensamento do, à época, ex-reitor da UCDB, Padre José Marinoni, sobre o que é extensão:

A extensão deve prestar serviço à comunidade. Além disso, que tenha por objetivo a 'melhoria da vida social do povo, [...] pois mais do que ficar em pesquisa pura [devem ser] pesquisas que promovam, que deem um resultado benéfico para melhorar a vida do cidadão'. Eu até ousaria dizer o seguinte: o ensino e a pesquisa devem desembocar num serviço de qualidade que se poderia resumir em extensão, isto é, não existe a extensão separada do ensino, separada da pesquisa, porque eu não posso entender que uma universidade comunitária me faça uma pesquisa de ponta em laboratório, gastando milhões, deixando morrer de fome ou morrer de inanição as pessoas que estão próximas dessa universidade. Então, que a pesquisa seja utilizada como pesquisa, mas ao mesmo tempo que essa pesquisa seja um serviço à comunidade. [...] O acadêmico tem que ser mentalizado de que ele realmente vive cercado por seres humanos, por pessoas, por semelhantes que não têm os mesmos privilégios que ele tem. Então eu vejo a extensão não como uma atividade à parte, eu a vejo muito estritamente relacionada com o ensino e a pesquisa. 
A UCDB, desde sua formação como Universidade, em 1994, tem grande preocupação com a extensão, tanto que no seu estatuto, artigo 6o - parágrafo IV, dispõe que seu objetivo é "Promover pesquisas e atividades de extensão que produzam e difundam conhecimentos em função das necessidades da maioria da população".

Este parágrafo reafirma a responsabilidade e a preocupação da UCDB com a extensão no sentido de alinhar o conhecimento produzido em seus mais diversos cursos, em sintonia com as demandas identificadas na sociedade.

\section{RÁDIO COMO FATOR DE INCLUSÃO SOCIAL: PROJETO RÁDIO Z}

A radiodifusão é um tipo de comunicação baseada na "fala", de característica exclusivamente humana.

A palavra falada é para a inteligência o que a roda é para os pés, pois Ihes permite deslocar-se de uma coisa a outra com desenvoltura e rapidez. A linguagem projeta e amplia o homem. A fala separa o homem e a humanidade do inconsciente cósmico. A linguagem é considerada a mais rica forma de arte humana, pois é que a distingue da criação animal. (MCLUHAN, 1964, p. 8).

Desta forma, a palavra falada tem valor indiscutível, e por meio desta linguagem pode-se transmitir paixão, sarcasmo, exasperação, ambiguidade, subserviência e cansaço, tudo isso por intermédio das mesmas palavras (NEGROPONTE, 1995, p. 134-5).

No Brasil, conforme Tavares (1999, p. 47-52) destaca:

[...] foi em 1922, ano em que foi descoberta a radiodifusão brasileira. Na ocasião o discurso do então Presidente da República, Sr. Epitácio da Silva Pessoa, chegou ao grande público por intermédio de um sistema de "telefone alto-falante", montado na praia vermelha, e de um transmissor instalado no alto do Corcovado pela Westinghouse. Para grande parte de pesquisadores, essa foi considerada a primeira emissora radiofônica que se implantou no Brasil. Devido à falta de uma documentação e a precariedade daquelas irradiações, persistirá a dúvida de que, se mesmo em caráter experimental e demonstrativo, aquela não terá sido efetivamente a primeira radioemissora a ser implantada em nosso país. Anterior a esta data, cujo registro jurídico de radiotelegrafia é o mais antigo do país, datando de 06 de abril de 1919, temos a Rádio Clube de Pernambuco, PRA-8, na cidade de Recife, antes Clube de Recepção de radiotelegrafia.

A primeira rádio brasileira surgiu no dia 20 de abril de 1923 - a PRA-2, Sociedade Rádio do Rio de Janeiro (atual Rádio Ministério da Educação e Cultura), implantada por Edgar Roquette Pinto e Henrique Morize.

As primeiras emissoras tinham sempre em sua denominação os termos "clubes" ou "sociedades", pois, de fato, nasciam como clubes ou associações formadas e financiadas por idealistas, com o objetivo de difundir a cultura e favorecer a integração nacional.

Nessa fase, as rádios se mantinham por meio de eventuais doações de empresas públicas e privadas, e de mensalidades pagas pelos proprietários de aparelhos receptores. Assim, apelos constantes eram feitos no sentido de conseguir a adesão de um número cada vez maior de sócios, de modo a manter as transmissões.

As estações de rádio criadas na década de 1920 tinham como principal característica o fato de não se constituírem em empreendimentos comerciais.

O conceito da radiodifusão modificou-se bastante com o passar dos anos, deixando de ser apenas uma fonte de educação e, de acordo com Sant'Anna (1982, p. 282): 
O rádio passou a ser uma fonte de diversão e entretenimento e, em grau menor, de informação e cultura. É por excelência um veículo de apelo popular, com o qual se pode atingir rapidamente grandes massas, tanto nas capitais, como nas cidades do interior, dado o vasto número de emissoras existentes em todo o País e o elevado número de receptores em uso.

Somente em 1931 que o serviço radiofônico foi regulamentado, quando Roquete Pinto entregou a rádio ao Governo Brasileiro. A partir do Decreto n. 21.111, de 10 de março de 1932, surgiu o tipo de radiodifusão mais comum no Brasil: a radiodifusão comercial, cuja autorização para a veiculação de propaganda (mensagens publicitárias) provocou grande mudança no conteúdo do rádio, que até então era erudito, instrutivo e cultural (BRASIL, 1932).

O rádio tornou-se o veículo de lazer e diversão. Nessa época, com o despertar do comércio, da indústria e de seus produtos que precisavam ser comercializados no mercado interno, o rádio encontrou o contexto ideal para sua expansão. Outro fato importante a ser mencionado, e que também chamou atenção dos empresários da época, era a eficiência do rádio em comparação aos outros veículos de comunicação impressa, já que a maioria da população continuava analfabeta.

Com o advento da publicidade no rádio, em forma de spot ou jingle, as emissoras trataram de se organizar como empresas para disputar o mercado, e, para fazer face a essa competição, investiram e contrataram artistas e produtores para criar seus anúncios.

Do início do século XX à atualidade, pode-se afirmar que o rádio rapidamente tomou conta do mundo inteiro, estabelecendo contato praticamente imediato entre o acontecimento, o fato, a informação e a notícia. Conforme McLuhan (1964, p. 336), “O rádio afeta as pessoas, digamos como que pessoalmente, oferecendo um mundo de comunicação não expressa entre o escritorlocutor e o ouvinte. Este é o aspecto mais imediato do rádio. Uma experiência particular".

Ruas (2004) afirma que o profundo poder de envolvimento do rádio, com os seus ouvintes, passa a se manifestar pelo uso que estes fazem do aparelho de rádio, inclusive enquanto executam seus trabalhos, dentro ou fora de casa, com um contato íntimo que os particularizava nas multidões.

A descoberta do transistor, em 23 de dezembro de 1947, enfatizou o aspecto da mobilidade que o rádio precisava para se popularizar ainda mais. Livre de fios e de tomadas, o rádio passou a estar presente em todos os lugares: na sala, na cozinha, no quarto, no carro, nas caminhadas, no bar, no trabalho. Onde estivesse o ouvinte, lá estava ele também: em qualquer situação, sem incomodar ninguém, fazendo parte do seu dia a dia, transformando-se no único meio de comunicação móvel do mundo, além da vantagem de poder ser operado de forma extremamente simples.

Essa mobilidade fez com que o rádio, um meio de comunicação de massa, deixasse de ser meio de recepção coletiva e se tornasse cada vez mais individual. Os emissores passaram a se comunicar, para toda a sua audiência, como se estivessem falando para cada um dos seus ouvintes, em particular.

O rádio tem duas frequências, sendo a Amplitude Modulada (AM) competindo com a Frequência Modulada (FM). Segundo Moreira e Bianco (2001, p. 65):

O rádio AM no Brasil sofreu profundas transformações desde o seu surgimento em 1922. Primeiro foram as rádios sociedades com sua programação elitizada. A entrada da publicidade, poucos anos depois, provocou um crescimento no setor, culminando com a época de ouro do rádio brasileiro. Na década de cinquenta surgem dificuldades com o aparecimento da TV e de todo seu glamour. [...] A entrada em funcionamento do transistor permitiu a mobilidade 
do aparelho rádio e poucos anos depois, o AM, na década de sessenta, voltou a sofrer um novo golpe com a entrada da Frequência Modulada, que trouxe uma qualidade melhor de som e um novo conceito de musicalidade com interação de ouvintes.

Esta nova opção de sintonia radiofônica (FM) surgiu para contemplar os ouvintes, principalmente das classes A e B, que se julgavam excluídos de programação, popular e eclética, transmitida na época pelas emissoras AM.

Houve fatores que viabilizaram esse processo, tais como o crescimento da população brasileira, a diversificação cada vez maior do público, provocando aumento extremamente significativo no número de emissoras de rádio. Para Santaella (1996), a proliferação de estações de rádio foi o fator que fortaleceu o sistema nacional de comunicação Esse fortalecimento tornou inquestionável a influência exercida pelos meios de comunicação no cotidiano da sociedade.

A mídia possui a capacidade de atingir o público, persuadi-lo e até atribuir simpatia ou repulsa aos fatos ou indivíduos, de acordo com sua conveniência. O rádio, como mídia, cumpre papel fundamental no cotidiano da sociedade brasileira, até os dias de hoje.

Para fazer uso deste instrumento poderoso que é o meio radiofônico, foi criado e produzido o programa Rádio Z: informação especial para você, cujo nome foi criado pelos alunos do curso de Publicidade e Propaganda da UCDB, em homenagem a Johann Heinrich Pestalozzi. De origem sueca, Pestalozzi era pedagogo, educador e pioneiro da reforma educacional; ele afirmava que só o amor tinha força salvadora, capaz de levar o homem à plena realização moral - isto é, encontrar conscientemente, dentro de si, a essência divina que Ihe dá liberdade.

A concretização deste produto radiofônico conta com vários atores trabalhando em prol de um único objetivo: a inclusão social. De um lado, os professores dos cursos de Publicidade e Jornalismo e seus acadêmicos; e, na outra ponta, os alunos da APCG. A realização de um projeto nestes moldes, contando com investimento de uma instituição de ensino superior privada, permite aos alunos um contato mais próximo com a realidade social e profissional, além do incentivo à produção acadêmica.

No caso deste projeto, especificamente, em função de sua estrutura, o aluno adentra o universo radiofônico, aliando teoria e prática na criação, produção (texto e sonoplastia), edição e veiculação dos programas. Como objetivo, pode-se citar: a) proporcionar aos acadêmicos uma proximidade maior com o universo dos meios de comunicação, permitindo que vejam e conheçam os seus bastidores; b) incentivar os alunos na pesquisa do dia a dia da propaganda, fazendo-os se aproximarem da realidade do mercado; c) estimular a produção acadêmica na área de jornalismo e publicidade; d) contribuir para o aperfeiçoamento e desenvolvimento dos alunos parceiros, criando ferramentas que viabilizem sua inclusão; e) estimular a realização de parcerias sociais, associando os conceitos teóricos e acadêmicos com a prática profissional; f) reconhecer a responsabilidade social que cada indivíduo desempenha socialmente, não somente como profissional, mas principalmente como cidadão.

Suas primeiras gravações foram em março de 2004 e, apesar das inúmeras dificuldades que a equipe passou, certos ingredientes foram compartilhados e colocados em prática, tais como paciência, ousadia e criatividade pela equipe do projeto. 
Figura 1 - Alunos da Associação Pestalozzi no estúdio de rádio com a professora profa. Cláudia Ruas, coordenadora do projeto

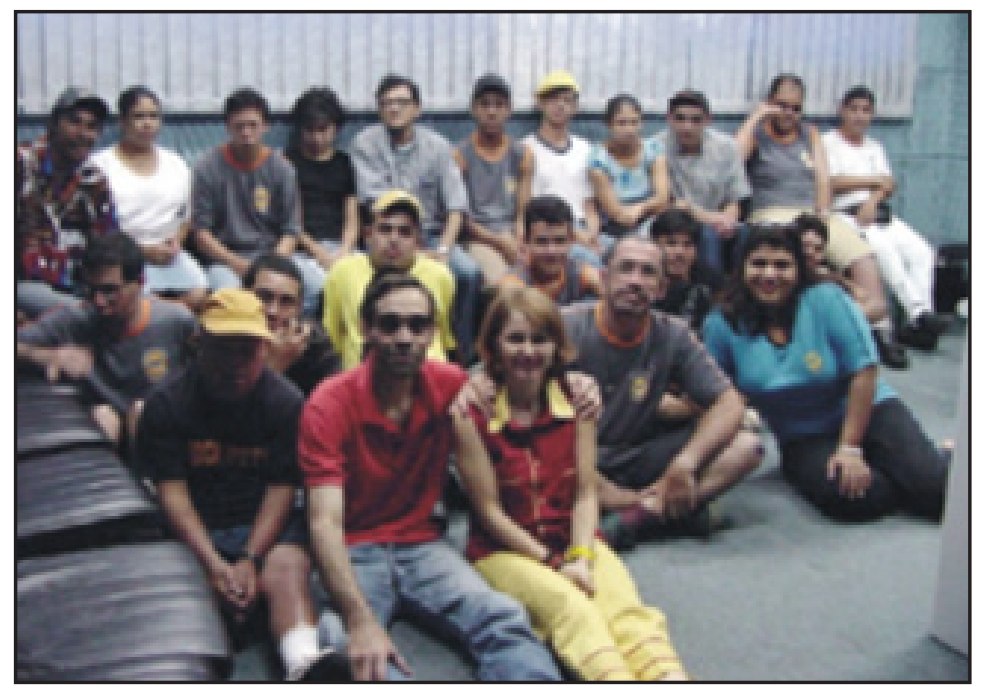

Fonte: Arquivo pessoal.

Figura 2 - Alunos da Associação Pestalozzi durante gravação do programa

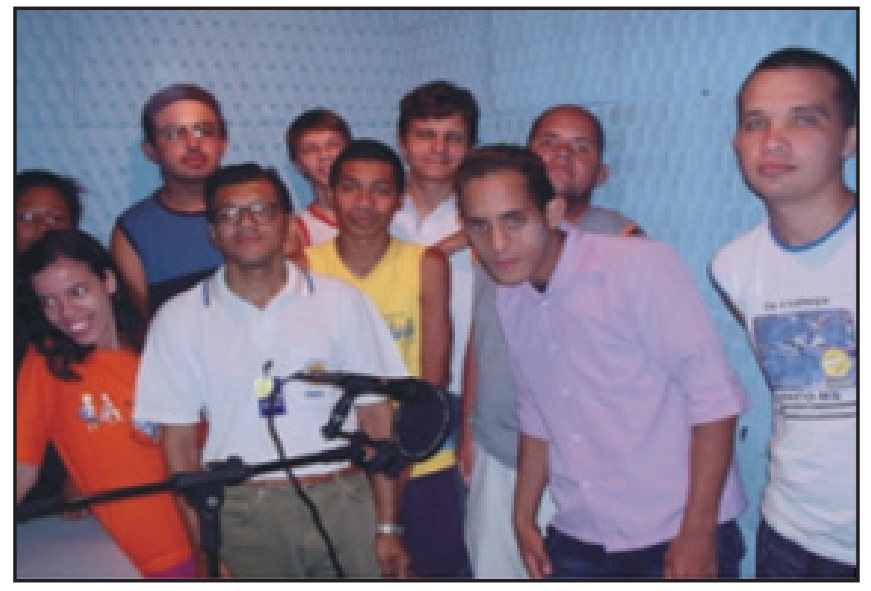

Fonte: Arquivo pessoal.

Figura 3 - Equipe do projeto discutindo pauta

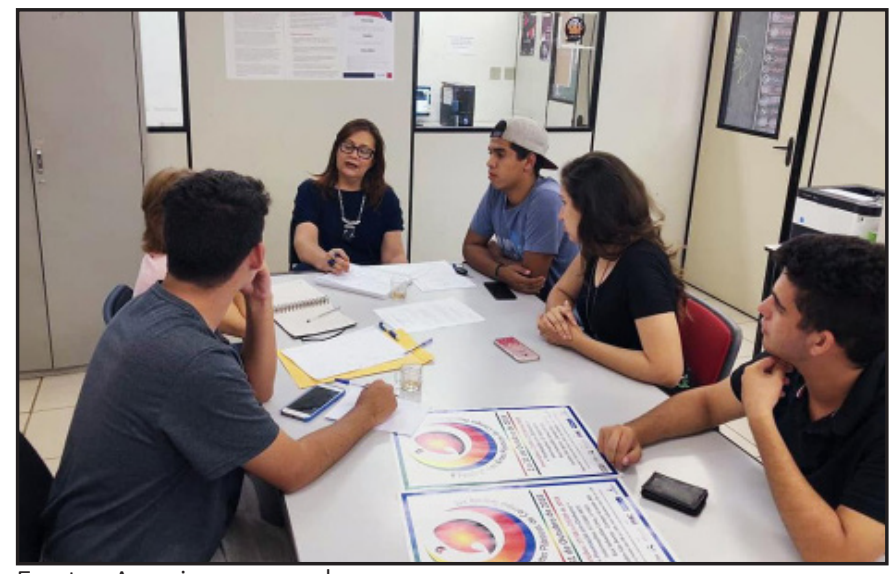

Fonte: Arquivo pessoal. 
Figura 4 - Equipe do projeto gravando a pauta

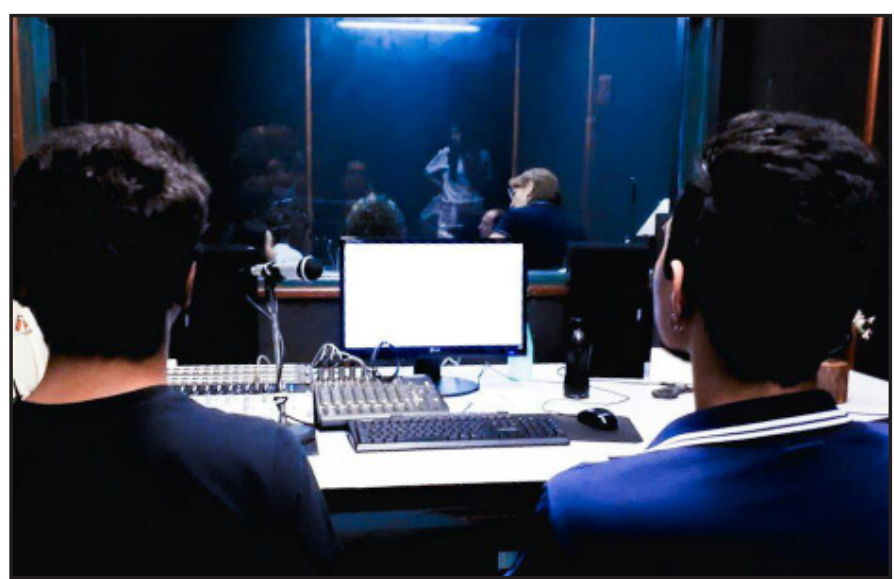

Fonte: Arquivo pessoal.

Em 2016, o projeto foi enriquecido com a participação de professores e alunos do curso de Jornalismo, cumprindo um importante papel da interdisciplinaridade.

A produção do programa conta com os alunos de jornalismo, cuja responsabilidade é pesquisar, discutir e escrever as pautas. Quanto aos alunos do curso de PP, a função é a criação de jingle, spots, trilhas sonoras para os programas que, atualmente, contam com conteúdo de utilidade pública.

O produto resultante deste projeto é um programa de um minuto veiculado na FM UCDB 91.5 e na emissora AM 580 Rádio Imaculada de Campo Grande, em diversos horários dentro da sua programação.

\section{CONSIDERAÇÕES FINAIS}

O projeto social que faz uso do meio radiofônico é uma forma de conciliar o poder exercido pelo rádio, sua função social e os conhecimentos específicos dos profissionais que podem otimizar a capacidade radiofônica de despertar, mobilizar e propiciar a informação para a construção de uma consciência mais voltada à responsabilidade social e ao resgate da cidadania, por meio da informação.

A UCDB, reconhecendo a necessidade em assumir sua responsabilidade social perante a comunidade campo-grandense, acreditou e aceitou o desafio de investir no projeto Rádio Z: Informação Especial para Você. Com isso, a instituição mostrou que é possível desenvolver um programa com características diferenciadas em prol de valores de cidadania, como a inclusão social.

Com a execução de um projeto de extensão neste formato, a UCDB mostra à sociedade que é possivel proporcionar a inclusão social, formatando parcerias diferenciadas, em que todos os envolvidos se beneficiam.

Para os alunos da Pestalozzi, observa-se, com a execução deste projeto, uma melhora da autoestima, aprimoramento das técnicas vocais e, o mais importante: a comprovação de que, dentro de seus limites, não há barreiras para informar, entreter e educar por meio do meio radiofônico. Quanto aos acadêmicos da UCDB, é possível constatar a aplicação da teoria de sala de aula, na prática, e o conhecimento de outra realidade certamente os tornam pessoas melhores e, consequentemente, como pessoas melhores terão subsídios para serem melhores profissionais. 


\section{REFERÊNCIAS}

BITTAR, Mariluce. O ensino superior privado no Brasil e a formação do segmento das universidades comunitárias. In: REUNIÃO ANUAL DA ANPED, 23., 2000, Caxambu, MG. Anais [...]. Caxambu: ANPED, 2000. Disponível em: http://23reuniao.anped.org.br/textos/1108T.PDF. Acesso em: 27 jun. 2012.

BITTAR, Mariluce. Educação superior: o "vale tudo" na mercantilização do ensino. Quaestio - Revista de Estudos em Educação, Sorocaba, v. 1, n. 1, p. 51-64, maio, 1999.

BRASIL. Ministério da Educação. Lei n. 5.540, de 28 de novembro de 1968. Fixa normas de organização e funcionamento do ensino superior e sua articulação com a escola média, e dá outras providências. Diário Oficial da União, 3 dez. 1968. Brasília, DF, 1968.

BRASIL. Decreto n. 21.111, de 10 de março de 1932. Aprova o regulamento para a execução dos serviços de radiocomunicação no território nacional. Diário Oficial da União, 4 mar. 1932, Seção 1. Brasília, DF, 1932. p. 3914.

DURHAM, Eunice Ribeiro; SAMPAIO, Helena. Ensino privado no Brasil. Documento de trabalho do Nupes. São Paulo, USP, n. 3, 1995.

MCLUHAN, Marshall Herbert. Os meios de comunicação como extensão do homem. São Paulo: Cutrix, 1964.

MOREIRA, Virginia; BIANCO, Nelia (Org.). Desafios do rádio no século XXI. Rio de Janeiro: UFRJ, 2001.

NEGROPONTE, Nicholas. A vida digital. São Paulo: Companhia das Letras, 1995.

RUAS, Claudia Mara Stapani. O modelo de gestão dos grandes oligopólios da educação. São Paulo: Livronovo, 2015.

RUAS, Claudia Mara Stapani. Rádio comunitária: uma estratégia para o desenvolvimento local. Campo Grande: UCDB, 2004.

SANT'ANNA, Armando. Propaganda: teoria, técnica e prática. 3. ed. São Paulo: Pioneira, 1982.

SANTAELLA, Lúcia. Cultura das mídias. São Paulo: Experimento, 1996.

SÍVERES, Luiz. A universidade e o compromisso social: a contribuição da extensão. Revista Diálogos, Brasília, DF, v. 5, p. 44-8, 2005. Disponível em: https://portalrevistas.ucb.br/index.php/RDL/article/view/1442/1081. Acesso em: 16 jul. 2018.

TAVARES, Reynaldo C. Histórias que o rádio não contou. 2. ed. São Paulo: Harbra, 1999.

\section{Sobre as autoras:}

Cláudia Ruas: Doutora em Educação e mestre em Desenvolvimento Local pela Universidade Católica Dom Bosco (UCDB). Docente no Curso de Comunicação da UCDB. E-mail: claudia@ucdb.br, Orcid: https://orcid.org/0000-0001-8793-2078

Inara Souza Silva: Mestre em Ciência da Informação pela Universidade de Brasília. Graduada em Comunicação Social, habilitação Jornalismo. E-mail: inarassilva@gmail.com, Orcid: https://orcid.org/0000-0002-31845319

Lorena Arantes do Socorro: Graduanda em Jornalismo pela Universidade Católica Dom Bosco (UCDB). Redatora na empresa Midiativa Comunicação Digital. E-mail: ra174572@ucdb.br, Orcid: https://orcid.org/0000-0002-9661-0801 